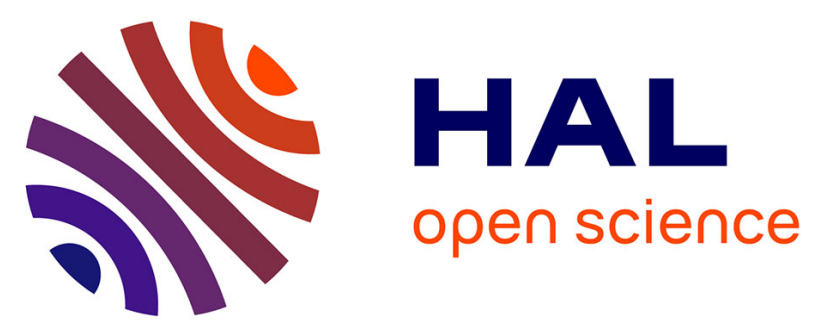

\title{
Electrical Ageing Modeling of the Insulation of Low Voltage Rotating Machines Fed by Inverters with the Design of Experiments (DoE) Method
}

\author{
Nadine Lahoud, Jérôme Faucher, David Malec, Pascal Maussion
}

\section{To cite this version:}

Nadine Lahoud, Jérôme Faucher, David Malec, Pascal Maussion. Electrical Ageing Modeling of the Insulation of Low Voltage Rotating Machines Fed by Inverters with the Design of Experiments (DoE) Method. SDEMPED 2011 8th IEEE International Symposium on Diagnostics for Electric Machines, Power Electronics and Drives, Sep 2011, Bologna, Italy. pp.272-277, 10.1109/DEMPED.2011.6063635 . hal-01289127

\section{HAL Id: hal-01289127 \\ https://hal.science/hal-01289127}

Submitted on 16 Mar 2016

HAL is a multi-disciplinary open access archive for the deposit and dissemination of scientific research documents, whether they are published or not. The documents may come from teaching and research institutions in France or abroad, or from public or private research centers.
L'archive ouverte pluridisciplinaire HAL, est destinée au dépôt et à la diffusion de documents scientifiques de niveau recherche, publiés ou non, émanant des établissements d'enseignement et de recherche français ou étrangers, des laboratoires publics ou privés. 


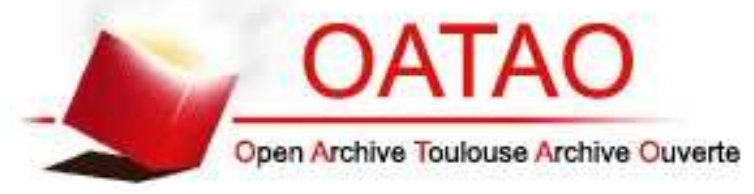

\section{Open Archive TOULOUSE Archive Ouverte (OATAO)}

OATAO is an open access repository that collects the work of Toulouse researchers and makes it freely available over the web where possible.

This is an author-deposited version published in : http://oatao.univ-toulouse.fr/ Eprints ID : 14464

To link to this article : DOI : 10.1109/DEMPED.2011.6063635

URL : http://dx.doi.org/10.1109/DEMPED.2011.6063635

To cite this version : Lahoud, Nadine and Faucher, Jérôme and Malec, David and Maussion, Pascal Electrical Ageing Modeling of the Insulation of Low Voltage Rotating Machines Fed by Inverters with the Design of Experiments(DoE)Method. (2011) In: SDEMPED 2011, 5 September 2011 - 8 September 2011 (Bologna, Italy).

Any correspondance concerning this service should be sent to the repository administrator: staff-oatao@ listes-diff.inp-toulouse.fr 


\title{
Electrical Ageing Modeling of the Insulation of Low Voltage Rotating Machines Fed by Inverters with the Design of Experiments (DoE) Method
}

\author{
Nadine Lahoud, Jérôme Faucher, David Malec, Pascal Maussion \\ University of Toulouse \\ LAPLACE (LAboratoire PLAsma et Conversion d'Energie) INPT, UPS, CNRS, Toulouse, France \\ pascal.maussion@laplace.univ-tlse.fr
}

\begin{abstract}
In the context of more electric aircrafts, the reliability of the low voltage insulation systems in rotating machines is an important issue. But, modeling and understanding their electrical ageing is a complex phenomenon especially when they are fed by PWM inverter. They involve a large amount of parameters related to both operating conditions and material design, which act together. Accelerated ageing tests are usually run in order to describe the electrical ageing process and to determine the lifetime of these materials. Nevertheless, full ageing tests with all the various parameters for different samples become rapidly time consuming. Moreover, there is not any complete model for insulation lifetime prediction under accelerated ageing tests. In this paper work, we propose a method based on the design of experiments (DoE) method, which is a useful statistical approach that would lead to a reliable and significant interpretation of the different ordering parameters of the insulation ageing process. Moreover, this method will help to reduce the number of required experimental or numerical trials and will, take into account the possible failure mechanisms and the various synergetic effects between them. Using the (DoE) method, a preliminary model of the insulation "lifetime" is presented with respect to the most important parameters at play and interactions between them.
\end{abstract}

Keywords: insulating and magnetic materials, remaining life models, ageing tests, design of experiments; ageing model

\section{INTRODUCTION}

Over the last decades, several models have been proposed for the electrical insulation life-end modeling [1-4] with respect to the physical, thermal and electro-mechanical aspects of the electrical ageing process. Despite these studies, this phenomenon remains complex and difficult to understand, forecast and at least model. Particularly, the rate of insulation degradation in rotating machines fed by inverters could be affected by many operating factors such as voltage, frequency, temperature, pressure... and these stresses could have many synergetic effects between them [4].

Accelerated ageing tests are usually undertaken in order to predict the insulation lifetime. These tests are used to obtain the failure statistics and determine a functional relationship between an applied stress (electrical, thermal, mechanical...) and the characteristic insulation lifetime. However, the choice of the applied stress and the lifetime forms remains critical. In this article, the "Design of Experiments" (DoE) method is used in order to compare and to validate two theoretical lifetime models presenting the same parameters, but with different forms. The first model presents the insulation lifetime variation with respect to a linear form of different external applied stresses. The second model takes into account logarithmic and exponential forms of the different parameters. These forms are chosen with respect to previous theoretical studies and some experimental results. In this study, the DoE method is briefly presented followed by the way this statistical method is applied on accelerated ageing test results in order to obtain and compare two mathematical lifetime models. For each one, an additional experimental test allows validating the theoretical result.

\section{The Design OF EXPERIMENTS (DoE) METHOD}

The history of design of experiments started in the 1930s in England with M. Fisher [5], but it knew an accelerating development since the publication of some predefined tables by Taguchi [6]. The principle of this methodology is to carry out a schedule of experiments designed to obtain the most accurate information for a specific problem with a minimum number of experiments $[7,8]$. Its advantages were proved in different areas of application, especially in chemistry and mechanics, where a large number of parameters have to be optimized simultaneously. This method has been used in electronics, circuits and devices, components and packaging, for the design optimization in some industrial electronics applications [9] and for powerful non linear control of power converters [10]. Different designs exist in order to go with a large number of applications, but the "Full factorial design" is chosen in this study.

\section{A. Full factorial designs}

Full factorial designs involve designing a set of experiments, in which all relevant parameters, called factors, are varied systematically. Thus, two levels, a high and a low, are chosen for each factor. The desired criterion, called the response, is measured for each combination of the different factor levels.

The main purpose of these designs is to gain information on the effects of the selected parameters. The idea is to modify 
the level of each factor in each experiment according to a specific procedure. This allows a drastic reduction of the number of required experiments, the possibility of taking into account much more parameters and the detection of interactions between factors. A very simple example with only two levels is presented in Table I. Centered reduced variables are used, i.e. (-1) for the low level and $(+1)$ for the high level of each factor. Each line represents an experiment and each column is indexed to a factor. For each experiment $(i)$, the selected criterion value $\left(y_{i}\right)$ is measured.

TABLE I: EXAMPLE OF AN EXPERIMENTAL TABLE

\begin{tabular}{|c|c|c|c|c|c|}
\hline $\begin{array}{c}\text { Experiment } \\
\text { number }\end{array}$ & & $\begin{array}{c}\text { Factor } \\
1\end{array}$ & $\begin{array}{c}\text { Factor } \\
2\end{array}$ & $\begin{array}{c}\text { Interaction } \\
12\end{array}$ & $\begin{array}{c}\text { Criterion } \\
\mathrm{Yi}\end{array}$ \\
\hline 1 & 1 & -1 & -1 & +1 & $\mathrm{y}_{1}$ \\
\hline 2 & 1 & +1 & -1 & -1 & $\mathrm{y}_{2}$ \\
\hline 3 & 1 & -1 & +1 & -1 & $\mathrm{y}_{3}$ \\
\hline 4 & 1 & +1 & +1 & +1 & $\mathrm{y}_{4}$ \\
\hline \multicolumn{5}{|r}{} & $\mathbf{M}$ \\
\cline { 5 - 6 }
\end{tabular}

According to the design of experiments methodology [14], the effect of a factor is obtained through (1). For example, $E_{1}=$ 0.12 means that the factor 1 at high level has an effect of +0.12 on the criterion with respect to the average value of the criterion, named $M$.

$$
E_{1}=\frac{-y 1+y 2-y 3+y 4}{4}
$$

Moreover, one keypoint of the DoE method is that the effect of interactions between factors 1 and 2 can also be determined. Equation (2) presents the average effect of interaction $E_{12}$ between factor 1 and 2, on the desired criterion.

$$
E_{12}=\frac{y 1-y 2-y 3+y 4}{4}
$$

Consequently, the mathematical model relating the response $Y$ to the different factors has the form of (3) :

$$
Y \sim M+E_{F 1} \cdot F_{1}+E_{F 2} \cdot F_{2}+E_{F 1 F 2} \cdot I_{F 1 F 2}
$$

where $Y$ is the response which represents the insulation lifetime in this case, $M$ is the mean value for all ageing test responses, $F_{i}$ are the factor levels affecting the ageing process, $I_{F i F j}$ are the interactions between factors $F i$ and $F j$, and $E_{i}$ are the effects of the factors or the effects of their interactions on the global response. It is also easy to verify that the effect vector $(\hat{E})$ can be calculated trough the following matricidal relationship:

$$
\hat{\mathrm{E}}=\mathrm{X}^{-1} \cdot \mathrm{Y}_{\mathrm{i}}
$$

$$
\text { with } \hat{E}=\left(\begin{array}{c}
M \\
E_{F 1} \\
E_{F 2} \\
E_{F 1 . F 2}
\end{array}\right)
$$

where $\hat{E}$ is the vector of the different factor effects on the criterion and their corresponding interactions, $X$ is the matrix obtained from the experience plan as shown in the light grey part of Table I and $Y_{i}$ is the vector of the experimental result values presented in the last column of Table I.

\section{B. Application of the DoE for lifetime modeling}

In the domain of electrical insulation degradation, the DoE method has already been used for tracking the influent operating parameters on the insulation lifetime of kapton films [11] and for the degradation analysis in terms of a better understanding of a reliable water-treeing test [12]. In this paper, the DoE method is used to analyze the ageing process of organic rotating machines insulation. The input variables are, in this case, the parameters affecting the insulation degradation and the process output is the insulation lifetime.

These designs include all combinations of every factor level. The number of experimental runs depends on the number of levels of each factor [13]. These designs are usually noted $X^{k}$, i.e. that the corresponding experiment table is composed of $k$ factors, with $X$ levels each.

As mentioned in the introduction, two mathematical models having the same parameters but with different forms, are defined by using this method. The first one presents a linear relationship between the response and the parameters. For the second model, the choice of the appropriate response and factor forms is explained in section IV-A-2.

\section{ACCElerated Ageing Tests}

Once the experimental design is chosen and the corresponding table is defined, accelerated ageing tests are performed in order to relate the applied external stresses (factors) to the insulation lifetime (response).

\section{A. Materials}

Rotating machines insulation is often made of polyesterimide (PEI) which is an organic material. Steel plates coated with PEI (thermal class: $180^{\circ} \mathrm{C}$ ) with a coating thickness of about $90 \mu \mathrm{m}$, as shown in Fig. 1, are subjected to an accelerated ageing test under different external stress conditions. Coated steel plates having an insulator thickness well controlled have been prefered to twisted pairs. Moreover, these kinds of samples have also been used to perform complementary measurements such as conduction current and dielectric strenght measurements which need to have a known insulator thickness as well. 


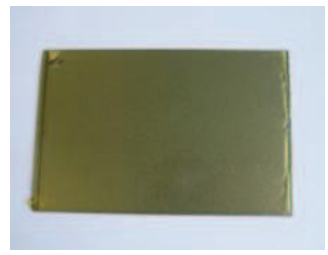

Fig. 1. Coated steel plate $(15 \mathrm{~cm} \mathrm{x} 9 \mathrm{~cm})$

For each test condition, the sample lifetime (i.e. when insulation properties fail or exceed the design limits) was measured. When a sample is broken down, the over-current is immediately detected by the HV-switch and the sample is switched off while the other ones remain supplied. Eight samples were simultaneously tested under each experimental condition. All lifetime data in this paper are presented either in terms of average values or using a Weibull's statistical treatment [14], which is commonly used for breakdown data treatment.

\section{B. Applied stresses}

Many different stresses can affect the insulation degradation phenomenon in rotating machines during normal service conditions, especially when fed by inverters. The failure process is driven by several stresses acting together such as electrical, thermal, mechanical and ambient (e.g. moisture, aggressive chemicals, dirt, radiation...). In rotating machines fed by inverters, over-voltages occur at the motor terminals and the voltage distribution in the winding is not homogeneous just after the voltage application. These over-voltages can lead to partial discharges occurring between phases, between turns or between turns and ground. In this study we consider the ageing of the insulation system due to a partial activity and not an intrinsic ageing. The experimental conditions of ageing have therefore been chosen in order to be sure that the insulation degradation is mainly due to the partial discharges. However, for the simplicity reasons, only three major parameters are studied for their corresponding ageing influence, which are:

- $\quad$ The applied voltage $(V)$

- $\quad$ The frequency of the applied voltage $(F)$

- The temperature $(T)$

\section{Experimental setup}

The samples are tested in our experimental setup, shown in Fig. 2. Under electrical stress, the steel plate behaves as one electrode whereas a spherical stainless steel electrode (diameter: $1 \mathrm{~mm}$ ) has been used as a second. The only pressure applied by the spherical electrodes on the sample is due to their mass $(0.8 \mathrm{~g})$. No additional springs have been used. At the same time, samples are placed in a climatic chamber where the applied temperature is fully controlled.

This study is a part of a research project whose aim is focused on the electric motors \& electronics for aeronautical applications in more electrical aircrafts. Two levels, a minimum and a maximum value, were defined for each stress with respect to this specific application.

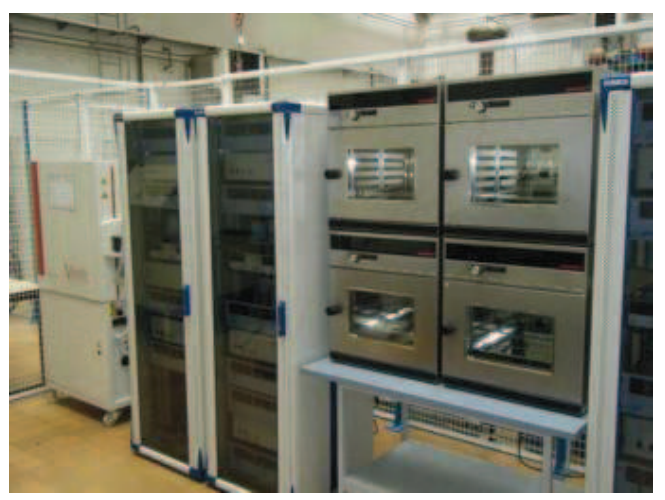

Fig. 2. Experimental steup for accelerated ageing tests

\section{The APPLICATION OF DESIGN OF EXPERIMENTS FOR THE INSULATION AGEING MODEL}

The traditional methodology for an experimental design consists on 4 steps: first the study preparation including the choice of the response and factor form, which is the main scope of this paper and the determination of factor levels, then the choice of the experimental design in the second step, the experiment itself and finally, the result analysis.

\section{A. Step 1: The study preparation}

\section{1) Choice of the response and factors form}

This paper presents two different ways for the insulation lifetime modeling. The first and simplest method is based on a linear relationship between the factors and the logarithm of the lifetime $\log (L)$. This approach was previously used for lifetime modeling of kapton films in [11], with a model described by (6):

$$
\begin{aligned}
& \log (L) \underset{ }{\sim} M+E_{V \cdot}(V)+E_{F \cdot}(F)+E_{T} \cdot(T)+E_{V F \cdot}(V) .(F)+ \\
& E_{V T \cdot}(V) \cdot(T)+E_{F T \cdot} \cdot(F) \cdot(T)+E_{V F T} \cdot(V) \cdot(F) \cdot(T)
\end{aligned}
$$

The second approach is based on previous knowledge from the domain. It will be shown that it leads to a more reliable model but requires specific factor levels. In this approach, the description of the insulation degradation in a partial discharge regime is taken into consideration. In this specific case, the effect of the electrical stress level on the insulation lifetime is most often represented by the inverse power model [15], such as in (7):

$$
L=c . E^{n}
$$

where $L$ is the insulation lifetime, $E$ is the electrical field, $c$ is a material constant and $n$ is called the power law constant. Our experimental results have shown that the lifetime evolution of our samples (for a given temperature and frequency) obeys well this relationship [16]. An inverse power relationship has also been found (for a given temperature and voltage) when the lifetime has been estimated versus frequency.

Moreover, under electro-thermal stress, our experimental results [16] and the state of the art showed that the variation of 
the insulation lifetime with temperature, at a fixed voltage and frequency, may follow (8):

$$
\log (L)=a \cdot \exp (-b . T)
$$

where $L$ is the insulation lifetime, $T$ is the applied temperature and $a$ and $b$ are material constants. Constant $\mathrm{b}$ is calculated from lifetime experimental results under electro-thermal stress. It is obtained by drawing the variation of the logarithm of the insulation lifetime with respect to the temperature (for a fixed $\mathrm{V}$ and $\mathrm{F}$ values). Its exact value is calculated from (8) on these experimental results as shown in [16]. This assumption will be used in our insulation lifetime model.

For the second model, we have chosen, according to (7) and (8), to study the variation of the logarithm of the lifetime with respect to a logarithm form of the electrical stress (i.e. the logarithm of the voltage and the frequency) and an exponential form of the temperature. Consequently, the corresponding model has the following form:

$$
\begin{aligned}
\log (L) \sim & M+E_{V \cdot} \cdot \log (V)+E_{F} \cdot \log (F)+E_{T} \cdot \exp (-b T)+ \\
& E_{F V} \cdot \log (V) \cdot \log (F)+E_{V T} \cdot \log (V) \cdot \exp (-b T)+ \\
& E_{F T} \cdot \log (F) \cdot \exp (-b T)+E_{V F T} \cdot \log (V) \cdot \log (F) \cdot \exp (-b T)
\end{aligned}
$$

\section{2) Determination of factor levels}

As already stated, three factors are chosen for this study: the applied voltage, the frequency and the temperature. The corresponding levels were chosen as follows:

- The extreme values of the applied voltage (square wave bipolar with $50 \%$ duty cycle) are $\pm 1 \mathrm{kV}$ and $\pm 3 \mathrm{kV}$ for its lower and higher value respectively. The lower value corresponds to a possible overvoltage in normal service conditions. Indeed, by considering a $500 \mathrm{Vdc}$ bus voltage and a complete impedance mismatch between the motor and its feeding cable, depending on the distance between the first turn of different phases and the last one, the voltage stress between them can rise up to $1 \mathrm{kV}$. The higher one is chosen to accelerate the ageing tests.
- $\quad$ The frequency extreme values are $5 \mathrm{kHz}$ and $15 \mathrm{kHz}$ for the lower and higher ones respectively that could be considered as normal PWM frequencies in these applications.

- The temperature extreme values are $-55^{\circ} \mathrm{C}$ for the lower one (aeronautic service conditions) and $180{ }^{\circ} \mathrm{C}$ for the higher (= thermal class of the insulating material) and also chosen in a way to accelerate the ageing tests.

Table II and III present the chosen factors with their corresponding form for models 1 and 2 respectively.

TABLE II. FACTOR LEVELS FOR MODEL 1

\begin{tabular}{|l|c|c|c|}
\hline \multicolumn{1}{|c|}{ Factors } & Level (-1) & Level (+1) & Level (0) \\
\hline Voltage $(\mathrm{kV})$ & 1 & 3 & 2 \\
\hline Frequency $(\mathrm{kHz}))$ & 5 & 15 & 10 \\
\hline Temperature $\left({ }^{\circ} \mathrm{C}\right)$ & -55 & 180 & 117,5 \\
\hline
\end{tabular}

TABLE III. FACTOR LEVELS FOR MODEL 2

\begin{tabular}{|l|c|c|c|}
\hline \multicolumn{1}{|c|}{ Factors } & Level (-1) & Level (+1) & Level (0) \\
\hline $\log ($ Voltage $(\mathrm{kV}))$ & $\log (1)$ & $\log (3)$ & $\log (1.73)$ \\
\hline $\log (($ Frequency $(\mathrm{kHz}))$ & $\log (5)$ & $\log (15)$ & $\log (8.7)$ \\
\hline $\operatorname{Exp}\left(-\mathrm{b} . \text { Temperature }\left({ }^{\circ} \mathrm{C}\right)\right)^{*}$ & $\operatorname{Exp}(55 \mathrm{~b})$ & $\operatorname{Exp}(-180 \mathrm{~b})$ & $\operatorname{Exp}(26.7 \mathrm{~b})$ \\
\hline
\end{tabular}

\section{B. Step 2 and 3: Choice of the experimental design and experimentation}

As already mentioned a "Full factorial design" is used for the accelerated ageing results analysis. The number of experiments to be done is $2^{3}$ ( 3 factors, 2 levels each). Table IV gives all the possible combinations between the different factor levels. Factors are $(V),(F)$ and $(T)$ for model 1 and $\log (V)$, $\log (F)$ and $\exp (-b T)$ for model 2. The corresponding experiment plan was carried out and the sample lifetime values are represented in Table IV (in the light grey columns). These columns present the Weibull treatment and the average values of eight samples simultaneously tested under each experimental condition. These values are very close and the Weibull

\begin{tabular}{|c|c|c|c|c|c|c|c|c|c|c|}
\hline \multirow{2}{*}{\multicolumn{2}{|c|}{$\begin{array}{l}\text { Model 1 } \\
\text { Model } 2\end{array}$}} & $\mathbf{V}$ & $\mathbf{F}$ & $\mathbf{T}$ & V.F & $\begin{array}{l}\text { V.T } \\
\end{array}$ & F.T & $\begin{array}{l}\text { V.F.T } \\
\end{array}$ & \multirow{2}{*}{\multicolumn{2}{|c|}{$\log (L)$}} \\
\hline & & $\log (V)$ & $\log (F)$ & $\exp (-b T)$ & $\log (V) \cdot \log (F)$ & $\log (V) \cdot \exp (-b T)$ & $\log (F) \cdot \exp (-b T)$ & $\log (V) \cdot \log (F) \cdot e^{(-b T)}$ & & \\
\hline Test $n^{\circ}$ & $M$ & $F 1$ & $F 2$ & $F 3$ & $I(V . F)$ & $I(V . T)$ & $I(F . T)$ & $I(V . F . T)$ & Weibull & Average \\
\hline 1 & 1 & -1 & -1 & -1 & 1 & 1 & 1 & -1 & 2,822 & 2,769 \\
\hline 2 & 1 & -1 & -1 & 1 & 1 & -1 & -1 & 1 & 1,452 & 1,431 \\
\hline 3 & 1 & -1 & 1 & -1 & -1 & 1 & -1 & 1 & 2,457 & 2,396 \\
\hline 4 & 1 & -1 & 1 & 1 & -1 & -1 & 1 & -1 & 1,165 & 1,154 \\
\hline 5 & 1 & 1 & -1 & -1 & -1 & -1 & 1 & 1 & 1,485 & 1,461 \\
\hline 6 & 1 & 1 & -1 & 1 & -1 & 1 & -1 & -1 & 0,805 & 0,793 \\
\hline 7 & 1 & 1 & 1 & -1 & 1 & -1 & -1 & -1 & 1,187 & 1,172 \\
\hline 8 & 1 & 1 & 1 & 1 & 1 & 1 & 1 & 1 & 0,2 & 0,196 \\
\hline \multicolumn{11}{|c|}{ Tests at the center of the study domain } \\
\hline \multicolumn{11}{|c|}{ Model 1: $\log (\mathrm{L})=\mathbf{f}(\mathrm{V}, \mathrm{F}$ and $\mathrm{T})$} \\
\hline 9 & 1 & 0 & 0 & 0 & 0 & 0 & 0 & 0 & 1.06 & 0.995 \\
\hline \multicolumn{11}{|c|}{ Model 2: $\log (L)=f[\log (V), \log (F)$ and $\exp (-b . T)]$} \\
\hline 10 & 1 & 0 & 0 & 0 & 0 & 0 & 0 & 0 & 1.44 & 1.417 \\
\hline
\end{tabular}
statistical treatment results, which are commonly used for breakdown analysis, have been chosen for this study.

TABLE IV. FULL FACTORIAL DESIGN MATRIX FOR THREE FACTORS WITH 2 LEVELS EACH 
It should be noticed that tests $n^{\circ} 9$ and 10 represent the experiments at the center of the study domain for models 1 and 2 respectively, as shown in Table II and Table III. These tests are run for the model validation, in order to compare the predicted lifetime and the experimental one at the center of the experimental domain.

\section{Step 4: Results Analysis}

As mentioned before, the application of (4) to our experimental design matrix and lifetime responses allows calculating the effects of the different factors and interactions on the sample lifetime. These effects are calculated for models 1 and 2 .

In order to verify the exactitude of the obtained mathematical models, an experimental test at the center of the level domain is undertaken. It is a point where factor and interaction levels are nil, which means the absence of any influence from factors and interactions with respect to the average value of the response $(M)$. In this case, according to the theoretical models, as shown in (6) and (9), the response should be equal to the mean $(M)$ of the ageing test values for each condition. In the following, the factors and interaction effect values, the mathematical form and verification will be presented for both models.

\section{1) Factors and interaction effect values}

The different effects are calculated by applying equation (4) on the experimental and the response matrices presented in Table IV. The different effect values are presented in Table $\mathrm{V}$ for both model 1 and 2.

TABLE V. ACTION EFFECT VALUES FOR MODELS 1 AND 2.

\begin{tabular}{|c|c|c|}
\hline Model 1 & Model 2 & Effect \\
\hline $\mathrm{M}$ & $\mathrm{M}$ & 1.45 \\
\hline $\mathrm{V}$ & $\log (\mathrm{V})$ & -0.53 \\
\hline $\mathrm{F}$ & $\log (\mathrm{F})$ & -0.19 \\
\hline $\mathrm{T}$ & $\operatorname{Exp}(-\mathrm{bT})$ & -0.54 \\
\hline $\mathrm{I}_{\text {V.F }}$ & $\mathrm{I}_{\mathrm{Log}(\mathrm{V}) \cdot \log (\mathrm{F})}$ & -0.03 \\
\hline $\mathrm{I}_{\text {V.T }}$ & $\mathrm{I}_{\mathrm{Log}(\mathrm{V}) \exp (-\mathrm{bT})}$ & 0.12 \\
\hline $\mathrm{I}_{\text {F.T }}$ & $\mathrm{I}_{\mathrm{Log}(\mathrm{F}) \cdot \exp (-\mathrm{bT})}$ & -0.03 \\
\hline $\mathrm{I}_{\text {V.F.T }}$ & $\mathrm{I}_{\mathrm{Log}(\mathrm{F}) \log (\mathrm{F}) \cdot \exp (-\mathrm{bT})}$ & -0.05 \\
\hline
\end{tabular}

Results of Table $\mathrm{V}$ may be presented in a diagram form as in Fig. 3. This diagram clearly shows the effect of each factor on the average value $(M)$ and the following conclusions could be deduced:

- The three factors (i.e. voltage, frequency and temperature) have a decreasing effect on the insulation lifetime.

- The voltage and the temperature effects are more important than the frequency effect.
- The most influent factors (i.e. voltage and temperature) have the highest interaction.
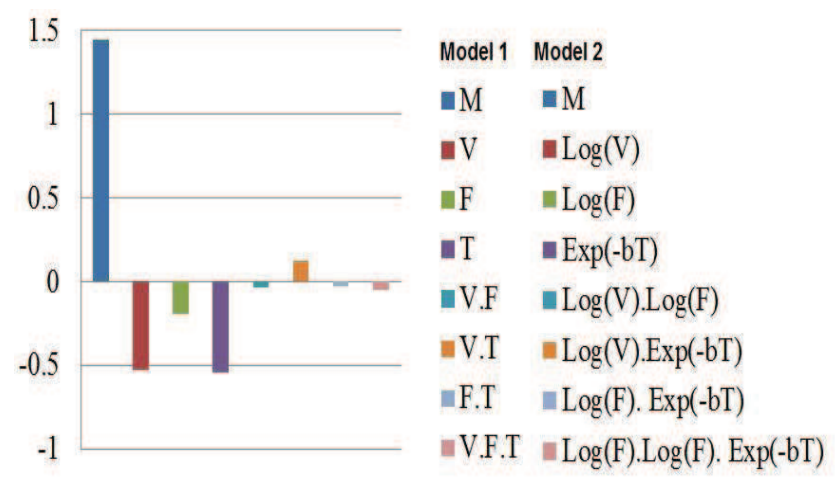

Fig. 3. The diagram effects for models 1 and 2

Bars of the bar-graph for each model in Figure 3, are shown in the order in Table V, ie for the first M, V for the second in model 1 and $\log (\mathrm{V})$ in model $2 \ldots$

\section{2) The mathematical models}

In order to obtain a mathematical form for model 1 , we should replace the different effect of (6) by their corresponding values in Table V. Thus, a mathematical model is obtained for the insulation lifetime with respect to the linear forms of the different parameters as in (10).

$$
\begin{array}{r}
\log (L) \sim 1.45-0.53 .(V)-0.19 .(F)-0.54 .(T)-0.03 .(V) .(F)+ \\
\text { 0.12.(V).(T) -0.03.(F).(T)-0.05.(V).(F).(T) }
\end{array}
$$

In the same way, the mathematical form of model 2 could be obtained using results from equation (9) and Table V. This model presents the variation of the logarithm of the lifetime with respect to a logarithmic form of the electrical stress and an exponential form of the temperature, as shown in (11).

$$
\begin{aligned}
\log (L) & \sim 1.45-0.53 \cdot \log (V)-0.19 \cdot \log (F)-0.54 \cdot \exp (-b T) \\
& -0.03 \cdot \log (V) \cdot \log (F)+0.12 \cdot \log (V) \cdot \exp (-b T) \\
& -0.03 \cdot \log (F) \cdot \exp (b T)-0.05 \cdot \log (V) \cdot \log (F) \cdot \exp (-b T)
\end{aligned}
$$

\section{3) Models verification}

An experimental test at the center of the level domain has been undertaken in order to verify the exactitude of each mathematical model.

For model 1, the center of the domain corresponds to $V=$ $2 \mathrm{kV}, F=10 \mathrm{kHz}$ and $T=117.5^{\circ} \mathrm{C}$ (cf. Table II). Lifetime results show that $\log (L)=1.06$. The theoretical value is 1.45 , which means that the error level between experiments and the model is of $26.9 \%$.

For model 2, this test is run for $V=1.73 \mathrm{kV}, F=8.7 \mathrm{kHz}$, and $T=26.7{ }^{\circ} \mathrm{C}$ (cf. Table III). Results show that $\log (L)=1.43$ at the center of the domain, which is very close to the theoretical value, i.e. 1.45 with only $1.4 \%$ of error. 


\section{CONCLUSION}

It has been shown, in a previous work of our research team, that the use of the DoE methodology is very useful for tracking the influent operating parameters on insulation reliability and for the lifetime modeling. In this study, two different lifetime models are defined and compared by using this method. Both models present a relationship between the insulation lifetime and the same external parameters, which are: voltage, frequency and temperature. The difference between these models comes from the form of these parameters.

The first model, which is the basic one, displays the lifetime variation with respect to a linear form of the different parameters. The second model takes into account a logarithm form of the electrical applied stress and an exponential form of the temperature. The definition of the parameter forms is based on previous knowledge in this domain and on experimental results.

Results of both models show that, in a partial discharge regime, the applied voltage and the temperature have a higher decreasing effect on the insulation lifetime than the frequency. Besides, these most influent factors have the highest interaction.

However, a significant disparity between the models arises from their correlation with experiments at the center of the study domain. Results show that model 1 presents a significant divergence, $26.9 \%$ of error, between theory and experiments. Model 2 shows only $1.4 \%$ of error between the theoretical and the experimental lifetime value at the center of the domain. Thus, the use of a linear form of the parameters to describe the variation of the insulation lifetime is not sufficient. A logarithm form of the electrical stress and an exponential form of the temperature should be integrated for a reliable description of the insulation lifetime.

\section{ACKNOWLEDGMENT}

This work makes part of the PREMEP project. PREMEP is a national collaborative research project, approved by the Aerospace Valley pole and focused on the electric motors \& electronics for aeronautical applications. The objective of PREMEP is to prepare new equipments for the new power supply network (230 Vac and $540 \mathrm{HV}_{\mathrm{DC}}$ ). The partners are Technofan, Liebherr Aerospace Toulouse, LAPLACE, CIRTEM, Ateliers de Navarre and DELTY.

\section{REFERENCES}

[1] G. Mazanti, G.C. Montanari and L.A. Dissado, "Electrical ageing and life models: The role of space charge," IEEE Trans. Dielect. Electr. Insul., vol. 12, no. 5, pp.876-890, October 2005.

[2] J.P Crine, "On the interpretation of some electrical aging and relaxation phenomena in solid dielectrics," IEEE Trans. Dielec. Elec. Insul., vol. 12, no. 6, pp. 1089-1107, December 2005.

[3] T.J. Lewis, “Ageing - A perspective”, IEEE Elect. Insul. Mag, vol. 7, no. 4, pp. 6-16, 2001.

[4] N. Lahoud, L. Boudou and J. Martinez-Vega, "A multi-dimensional model to describe the ageing process of polymers used for electrical insulation", in Proc. 2007 IEEE Inter. Conf. Sol. Dielec., Winchester UK, pp. 79-82.

[5] R.A. Fisher, The Design of Experiments, Edinburgh, Oliver and Boyd, 1935.

[6] Taguchi, G., Orthogonal arrays and linear graph, American Supplier Institute Press, 1987.

[7] A. C. Atkinson, A. N. Donev, Optimum Experimental Designs, Oxford University Press, New York. 1992.

[8] D.C. Montgomery, Design and Analysis of Experiments, John Wiley $\&$ Sons, Inc, 2005.

[9] L. Teck-Seng, C. Shixin and G. Xianke, "Robust torque optimization for BLDC spindle motors," IEEE Trans. Ind. Electr., vol. 48, no.3, pp. 656-663, June 2001.

[10] J. Faucher, P. Maussion "On-line electrical quality improvement of a single-phase boost rectifier with fuzzy controller and experimental designs", Electromotion, vol. 13, no. 3, July - September, 2006.

[11] Y. Khelil, P. Maussion, T. Lebey, "Experimental designs for tracking the influent operating parameters on insulation reliability", in SDEMPED 2009, Cargèse, France.

[12] J.P. Crine, "When Taguchi meets water treeing," IEEE Electr. Insul. Mag., vol. 16, no. 3, pp. 13-18, 2000.

[13] M. Tanco, N. Costa and E. Viles, "Experimental design selection: guidelines for practitioners," Int. J. Prod. Qual. Manag., vol. 4, no. 3, pp. 283-302, 2009.

[14] W. Weibull, "A statistical distribution function of wide applicability", ASME J. Appl. Mech., pp. 293-297, 1951.

[15] G. Stone, E.A. Boulter, I. Culbert and H. Dhirani, Electrical insulation for rotating machines, IEEE Press, J. Wiley \& Sons, 2004.

[16] N. Lahoud, M.Q. Nguyen, P. Maussion, D. Malec, D. Mary, "Using the Design of Experiments (DoE) to Elaborate an Electrical Ageing Model for the Insulation of Low Voltage Rotating Machines Fed by Inverters", in Proc. 2010 IEEE Int. Conf. Sol. Dielectr. (Potsdam Germany), pp. 24-27. 